\title{
A atuação do professor de Música diante da diversidade musical: reflexões e possibilidades
}

\author{
The music teacher's performance before musical \\ diversity: reflections and possibilities \\ El desempeño del profesor de música ante la \\ diversidad musical: reflexiones y posibilidades
}

\author{
AléCIO DA SilVA Veloso (HTTPS://ORCID.ORG/0000-0002-5712-1175) \\ GabRiel SÁvio Vieira da Silva (HTTPS://ORCID.ORG/0000-0002-6791-4785) \\ DANILO RAPOSO FREITAS (HTTPS://ORCID.ORG/0000-0001-6832-0391)
}

GABRIEL NUNES LOPES FERREIRA (HTTPS://ORCID.ORG/0000-0001-9617-1880)

Resumo

O presente artigo tem como objetivo compreender as possibilidades teóricas e práticas para o trabalho com a diversidade musical em sala de aula em diversos contextos formativos. Diante desses fatos, surgiram diversos questionamentos acerca da prática docente no campo da Educação Musical acerca da diversidade musical e as dificuldades

\footnotetext{
${ }^{1}$ Universidade Federal do Piauí (UFPI), Teresina, PI, Brasil. Licenciando em Música, e-mail: alecioguitar910@gmail.com.

2 Universidade Federal do Piauí (UFPI), Teresina, PI, Brasil. Licenciando em Música, e-mail: gabrielartorio19552009@gmail.com.

3 Universidade Federal do Piauí (UFPI), Teresina, PI, Brasil. Licenciando em Música, e-mail: daniloraposo.2012@gmail.com.

${ }^{4}$ Universidade Federal do Piaú (UFPI), Teresina, PI, Brasil. Doutor em Educação, e-mail: gabrielnlf@ufpi.edu.br.

Rev. Caminhos da Educação: diálogos, culturas e diversidades, Teresina, v. 2, n. 2, p.124-139, mai./ago. 2020
} 
para o trabalho pedagógico nesse âmbito. Assim, as perguntas norteadoras do estudo são: como lidar com a diversidade musical a que se depara o professor de música em sala de aula? Que teorias podem ser utilizadas para embasar essas práticas? Quais atividades podem ser utilizadas em sala de aula? Nesse sentido, faz-se necessário entender o processo formativo do professor de música no Brasil (FUCCI AMATO, 2006) e como acontece a formação do gosto musical das pessoas (BOURDIEU, 2007; 2009). Ressalta-se que esse trabalho se faz relevante por propor reflexões sobre o processo de ensino e aprendizagem do campo musical, além de propostas teóricas e práticas que dialogam com a diversidade tão presente nos diversos contextos com ensino de música. A partir das leituras e reflexões apresentadas no texto, percebemos a dificuldade na formação do professor de música tendo em vista o tradicionalismo e reprodução de métodos e técnicas desse campo, as possibilidades do trabalho com música pensando o repertório dos estudantes e a diversidade na sala de aula, o fazer musical contextualizado e indo além da técnica instrumental e também a importância de uma formação musical crítica e que seja, a cada dia, mais democrática.

Palavras-chave: Atuação docente. Habitus Conservatorial. Capital Cultural. Diversidade musical. Gosto Musical.

\begin{abstract}
This article aims to understand the theoretical and practical possibilities of working with musical diversity in the classroom in different contexts. Given these facts, several questions arose about the teaching practice in the field of Music Education regarding musical diversity and the difficulties for pedagogical work in this context. The guiding questions of this study are: How to deal with the musical variety faced by the music teacher in the classroom? What theories can support these practices? What activities can be used in the school? In this sense, it is necessary to understand the formative process of the music teacher in Brazil (FUCCI AMATO, 2006) and how the formation of people's musical taste happens (BOURDIEU, 2007; 2009). This work is relevant for proposing reflections on the process of teaching and learning in the musical field, in addition to theoretical and practical proposals that communicate with the diversity so present in the different contexts with music teaching. Considering the readings and reflections presented in the text, we realize the difficulty in training music teachers in view of the traditionalism and reproduction of methods and techniques in this field, the possibilities of working with music thinking about the students' repertoire and the diversity in the classroom and create a musical context that consider more than just the instrumental technique but also the importance of a even more democratic critical musical formation.
\end{abstract}

Keywords: Teaching performance. Conservatory Habitus. Cultural capital. Musical diversity. Musical taste.

\title{
Resumen
}

El presente artículo tiene como objetivo comprender las posibilidades teóricas y prácticas para trabajar con la diversidad musical en el salón de clases en diferentes contextos de capacitación. Delante de estas afirmaciones, surgieron varias preguntas sobre la práctica

Rev. Caminhos da Educação: diálogos, culturas e diversidades, Teresina, v. 2, n. 2, p.124-139, mai./ago. 2020 
docente en el campo de la Educación Musical sobre la diversidad musical y las dificultades para el trabajo pedagógico en este contexto. Por lo tanto, las preguntas orientadoras del estudio: ¿Cómo lidiar con la diversidad musical en clase? ¿Qué teorías pueden usarse para basar estas prácticas? ¿Qué actividades se pueden usar en la clase? En este sentido, es necesario comprender el proceso formativo del profesor de música en Brasil (FUCCI AMATO, 2006) y cómo ocurre la formación del gusto musical de las personas (BOURDIEU, 2007; 2009). Cabe destacar que este trabajo es relevante para proponer reflexiones sobre el proceso de enseñanza y aprendizaje en el campo musical, además de propuestas teóricas y prácticas que dialogan con la diversidad tan presente en diferentes contextos de la enseñanza de la música. A partir de las lecturas y reflexiones presentadas en el texto, nos damos cuenta de la dificultad en la formación de profesores de música en vista del tradicionalismo y la reproducción de métodos y técnicas en este campo, las posibilidades de trabajar con la música pensando en el repertorio de los estudiantes y la diversidad en clase. El hacer musical contextualizando y yendo más allá de la técnica instrumental teniendo en cuenta también la importancia de una formación musical crítica que, cada día, sea más democrática.

Palabras-clave: Desempeño docente. Hábitat conservatorio. Capital cultural Diversidad musical. Gusto musical.

\section{Introdução}

A sociedade contemporânea é caracterizada pela multiculturalidade, fenômeno esse que se configura como movimento social compartilhado por diversos grupos ou identidades culturais (LAZZARIN, 2008). Isso aconteceu pelas diversas mudanças sociais e culturais que ocorreram devido a fenômenos como o neoliberalismo e a globalização (SOUSA E IVENICKI, 2016). Essas mudanças podem gerar fenômenos tanto positivos, como, por exemplo, hibridizações culturais, como negativos a partir de práticas racistas e discriminatórias (SOUSA E IVENICKI, 2016).

O multiculturalismo participa desse movimento e muitas vezes celebra a instituição escolar como lugar de transformação social, ao mesmo tempo em que esconde os conflitos envolvidos nesse processo (LAZZARIN, 2008).

Rev. Caminhos da Educação: diálogos, culturas e diversidades, Teresina, v. 2, n. 2, p.124-139, mai./ago. 2020 
Diante desses fatos, surgiram diversos questionamentos acerca da prática docente no campo da diversidade musical e as dificuldades para o trabalho pedagógico nesse âmbito. Nesse sentido, como lidar com a diversidade musical a que se depara o professor de música em sala de aula? Que atividades podem ser utilizadas? Que teorias e teóricos podem ser pensados para embasar essas práticas?

Assim, objetiva-se com esse estudo compreender as possibilidades teóricas e práticas para o trabalho com a diversidade musical em sala de aula em diversos contextos formativos.

O presente estudo se justifica pela importância de compreender a diversidade musical dos estudantes indo além de uma postura de exclusão do que o aluno sabe e conhece. Além disso, o artigo traz importantes reflexões para o professor de música tanto no que diz respeito à formação do gosto musical, como também sobre sua própria formação e atuação.

Assim, a partir do exposto, faz-se necessário investigar como ocorre a formação do professor de música e também os conceitos de capital cultural e suas influências na formação do gosto musical das pessoas, para assim, traçar caminhos que possam contribuir para que o educador musical possa refletir sobre suas práticas e sempre buscar possibilidades para um melhor trabalho com a questão das diferenças.

\section{Formação do professor de música no Brasil e o habitus conservatorial}

De acordo com Fucci Amato (2006), as mudanças na Educação Musical no Brasil começaram a partir de 1920. Nesse mesmo período, surgiram nas escolas públicas de São Paulo modelos de musicalização, mas somente na década de 1930/40 "se implantou o ensino de música nas escolas em âmbito nacional, com a criação da Superintendência de Educação Musical e Artística (SEMA) por Villa-Lobos, a qual objetivava a realização da orientação, do planejamento e do desenvolvimento do estudo da música nas escolas, em todos os níveis" (FUCCI AMATO, 2006, p. 151).

Rev. Caminhos da Educação: diálogos, culturas e diversidades, Teresina, v. 2, n. 2, p.124-139, mai./ago. 2020 
Como reflexo desse projeto e no que diz respeito à formação de professores de música, podemos destacar o surgimento, em 1942, do Conservatório Brasileiro de Canto Orfeônico. Essa instituição tinha a finalidade de preparar professores para ministrar música nas escolas através do Canto Orfeônico (FUCCI AMATO, 2006). Esse cenário da educação musical no país com o ensino do canto orfeônico percorreu por alguns anos mesmo com algumas alterações nos currículos escolares. Em 1961, o canto orfeônico foi substituído pela Educação Musical que se estabeleceu nas escolas até 1970 .

Em 1971 ocorreu um fato que gerou grande mudança na área da docência musical. Fucci Amato (2006, p. 152) destaca que “com a LDB 5692/71 o Conselho Federal de Educação instituiu o curso de licenciatura em Educação Artística (Parecer n $1284 / 73)$ ". Nesse sentido, o currículo do curso de música foi alterado. O novo currículo passou a ser composto com quatro áreas das artes: música, artes plástica, artes cênicas e desenho.

Assim, a Educação Artística passou a fazer parte do currículo escolar como atividade obrigatória no ensino fundamental e médio. Em meio a essas alterações, os cursos superiores passaram a ofertar, o curso de Licenciatura em Educação Artística com habilitação em Música para aqueles que escolhessem atuar na área da docência no âmbito musical. Além disso, havia o curso de bacharel em música com habilitação em instrumento, canto, composição e regência (FUCCI AMATO, 2006).

Diante dessas transformações, Fucci Amato (2006) destaca que o número de professores formados em Educação Artística era bem inferior ao número de aulas nas escolas. Para atender essa demanda, a Secretaria de Educação de São Paulo elaborou um guia curricular para auxiliar no trabalho docente e conferiu direito para que antigos professores de música, desenho e artes industriais pudessem atuar na área. Apesar disso, esse guia foi elaborado sem fundamentos filosóficos, pedagógicos e psicológicos e não sugeria bibliografias que auxiliasse o trabalho desses professores.

Em 1996 surge a Lei de Diretrizes e Bases (LDB) nº 9.394 que estabeleceu o ensino de Arte na educação básica. Segundo Penna (2004, p. 23) nessa LDB:

[...] "o ensino da arte constituirá componente curricular obrigatório, nos diversos níveis da educação básica, de forma a promover o desenvolvimento cultural dos alunos" (Lei

Rev. Caminhos da Educação: diálogos, culturas e diversidades, Teresina, v. 2, n. 2, p.124-139, mai./ago. 2020 
9.394/96 - art. 26, parágrafo $2^{\circ}$ ), garante um espaço para a(s) arte(s) na escola, como já estabelecido em 1971, com a inclusão da Educação Artística no currículo pleno. E continuam a persistir a indefinição e ambiguidade que permitem a multiplicidade, uma vez que a expressão "ensino de arte" pode ter diferentes interpretações, sendo necessário defini-la com maior precisão.

Toda essa realidade reflete na formação e na atuação do professor de música da atualidade tendo em vista que em muitas escolas ainda não existe a disciplina Música e sim Arte, mas a formação do professor de música está relacionada integralmente com os elementos sistematizados do campo musical.

Além disso, a formação no ensino superior de música no Brasil tem sido marcada, por exemplo, pelo ensino com moldes do ofício medieval, o foco no músico professor como objetivo final do ensino e também com uma proposta tutorial, ou seja, aula de forma individual, a música erudita ocidental como o repertório legitimado, a seleção de estudantes baseando-se na perspectiva do "dom", dentre outras características (PEREIRA, 2014). Isso ocorre devido a forte presença de um habitus conservatorial no ensino de música.

Para entendermos esse conceito, faz-se necessário recorrer a noção de babitus na perspectiva de Pierre Bourdieu (2009). Segundo o autor, o habitus é um sistema:

[...] de disposições duráveis e transponíveis, estruturas estruturadas predispostas a funcionar como estruturas estruturantes, ou seja, como princípios geradores e organizadores de práticas e de representações que podem ser objetivamente adaptadas ao seu objetivo sem supor a intenção consciente de fins e o domínio expresso das operações necessárias para alcançá-los, objetivamente "reguladas" e regulares sem em nada ser o produtor da obediência a algumas regras e, sendo tudo isso, coletivamente orquestradas sem ser o produto da ação organizadora de um maestro (BOURDIEU, 2009, p. 87).

Já o habitus conservatorial segundo Pereira (2014, p. 94):

[...] seria próprio do campo artístico musical e estaria transposto (convertido) ao campo educativo na interrelação estabelecida entre estes dois campos. E seria incorporado nos agentes ao longo do tempo no contato com a instituição, com suas práticas, com seu currículo enquanto objetivação de uma ideologia. Assim, as instituições de ensino musical - como resultado da história iniciada pelos conservatórios - poderiam ser entendidas como opus operatum: campo de disputas que tem no habitus conservatorial o seu modus operandi.

Assim fica compreensível os motivos que levaram o "ensino formal de música [ser] conhecido por ter uma forte vinculação com a tradição conservatorial nas práticas comuns adotadas pelos professores de música” (RIBEIRO, 2018, p. 285).

Rev. Caminhos da Educação: diálogos, culturas e diversidades, Teresina, v. 2, n. 2, p.124-139, mai./ago. 2020 
Isso reflete de diversas formas em como o ensino de música se faz presente nos diversos espaços formativos na atualidade.

O habitus conservatorial garante aos currículos uma forma própria para o estudo da música erudita ocidental que não é aplicável às músicas populares e étnicas - e até mesmo às formas eruditas de música não ocidental. $\mathrm{O}$ trabalho com a cultura passa a lidar com produtos, no plural, mas não com a pluralidade necessária de processos. É mister, portanto, conscientizar-se de que os critérios de seleção curricular se orientam por um habitus que privilegia apenas uma estética pretensamente autônoma que se baseia apenas em significados inerentes da música erudita (PEREIRA, 2014, p. 100).

A partir do entendimento acerca das estruturas que influenciaram e influenciam a atuação e formação de professores de música é importante compreender as estruturas teóricas que dialogam com a diversidade musical no cotidiano das pessoas a partir do conceito de capital cultural (BOURDIEU, 2012).

\section{Capital cultural e diversidade musical}

A partir da explicação do habitus e habitus conservatorial no campo da música, faz-se necessário, para compreensão da diversidade musical, o entendimento acerca do que vem a ser capital e capital cultural.

De acordo com Abreu (2018, p. 47):

O conceito de capital diz respeito aos diversos saberes, fatos culturais, elementos capitais não restrito apenas ao conhecido capital capitalista, ou seja, o financeiro, mas sim, qualquer espécie ou forma de capital. É este capital, moeda não monetária, posso até dizer moeda simbólica, que à medida que é adquirido e incorporado pelos agentes passará a constituir o Habitus.

Já “o capital cultural relaciona-se a toda bagagem cultural adquirida pelo indivíduo no decorrer de sua vida, transmitidos e inculcados principalmente no ambiente familiar e na escola, e incluem competência linguística, diversos saberes, visão de mundo, apreço pela arte, gostos, etc" (CAMPOS E CREPALDE, 2016, p. 24).

Importante ressaltar que "as mídias fazem parte da cultura contemporânea e nela desempenham papéis cada vez mais importantes" (BÉVORT E BELLONI, 2009, p.1083 apud BUENO, COSTA e BUENO, 2012, p. 496). Trata-se de um

Rev. Caminhos da Educação: diálogos, culturas e diversidades, Teresina, v. 2, n. 2, p.124-139, mai./ago. 2020 
aspecto fundamental para a educação musical atual tendo em vista os novos modos de fazer e ouvir música (BUENO, COSTA E BUENO, 2012).

Nesse contexto, torna-se fundamental para o professor de música a compreensão de como o capital cultural e o habitus dialoga com a formação das pessoas e como o ambiente social influencia nesse diálogo através da mídia, da escola, amigos e etc.

Conforme se pôde constatar em Bourdieu (2006), o habitus exerce uma importante influência na realidade do sujeito social. Percebe-se adiante na discussão em torno das categorias de campo, habitus e capital, que elas estão imbricadas. É mediante a forma como elas se articulam na trajetória do sujeito que se configuram as realidades sociais (ABREU, 2018, p. 25).

Por fim, deve-se considerar que, desde que os estudos iniciais de Pierre Bourdieu, a difusão da mídia tem gerado uma ampla gama de gostos e práticas culturais.

[...] o crescimento vertiginoso no uso de computadores e o advento da internet também têm implicado em um contexto cultural mais complexo e amplo no que diz respeito ao consumo de música. Ademais, com o advento das gravações musicais, a música passou a exercer um papel ainda mais central em grande parte das subculturas populares, em especial, em grupos desfavorecidos, grupos jovens e em minorias étnicas (MAGLIONI et al, 2015, p.56).

A partir disso, entendemos a complexidade da formação do gosto musical a partir do conceito de habitus e capital cultural, mas é fundamental também a compreensão acerca da diversidade de gostos a partir do diferentes contextos e influências tanto familiares, midiáticas e também de outros espaços formativos.

Nesse contexto, torna-se fundamental o entendimento acerca das diferenças de gostos nos contextos formativos, tendo em vista o caráter multicultural de nossa sociedade e também as abordagens de como trabalhar com essa diversidade musical e cultural. Como vimos, anteriormente, nas discussões acerca da hegemonia de um repertório tradicional ocidental, por exemplo, desconsideramos muitas vezes as experiências e vivências musicais dos estudantes tanto na perspectiva do gosto e repertório musical como também dos conhecimentos prévios dos alunos.

Além disso, conforme Pereira (2014, p. 91) na formação do professor de música para atuação na educação básica “os currículos parecem desconsiderar a Rev. Caminhos da Educação: diálogos, culturas e diversidades, Teresina, v. 2, n. 2, p.124-139, mai./ago. 2020 
realidade musical [das] escolas e, principalmente, de seus alunos". Assim, torna-se de grande relevância refletir e propor ações acerca desse trabalho com a diversidade a partir dos próprios estudantes. Para isso, será explicitado, a seguir, alguns educadores musicais que trazem propostas que vão além do tradicionalismo na formação musical para, posteriormente, discutirmos sobre algumas possibilidades para o trabalho com a diversidade musical.

\section{Educadores musicais e propostas para o ensino de música}

Diante das reflexões apresentadas anteriormente sobre a formação do professor de música e também sobre a formação do gosto musical e o trabalho com a diversidade musical, é importante conhecer algumas propostas dentro do campo da Educação Musical que podem ser dialógicas com o fazer musical consciente em um contexto multicultural.

Assim, utilizaremos algumas teorias e propostas que vão além do tradicionalismo característico do habitus conservatorial objetivando uma experiência musical que parte da vivência e do conhecimento prévio dos estudantes. Como teóricos para o presente estudos foram escolhidos Swanwick (2003), Schafer (1991, 2001) e Dalcroze (Suiça, 1865-1950) por pensarem em propostas mais inovadoras no campo da Educação Musical e que possibilitam um trabalho musical mais consciente, crítico e diversificado.

Swanwick $(1979,1988)$, durante seus estudos, teve como foco pesquisas acerca da compreensão musical e desenvolveu, por exemplo, a Teoria Espiral do Desenvolvimento Musical, o modelo $(\mathrm{C}) \mathrm{L}(\mathrm{A}) \mathrm{S}(\mathrm{P})$ e também os três princípios de Educação Musical $^{1}$ (FRANÇA, 2018). Para o presente estudo, é fundamental a compreensão de seu modelo $(\mathrm{C}) \mathrm{L}(\mathrm{A}) \mathrm{S}(\mathrm{P})$ e também um dos princípios de Educação Musical que dialoga com o discurso (musical) dos alunos.

Sobre o $(\mathrm{C}) \mathrm{L}(\mathrm{A}) \mathrm{S}(\mathrm{P})$ :

[...] Swanwick volta-se para a educação e vê no professor o agente que pode fortalecer o relacionamento entre os estudantes e a música. Na busca de uma educação musical

\footnotetext{
${ }^{1}$ Para Swanwick (2003) a Educação Musical possui três princípios: 1. Considerar a música como discurso; 2. Considerar o discurso musical dos alunos e; 3 . Fluência no início e no final.

Rev. Caminhos da Educação: diálogos, culturas e diversidades, Teresina, v. 2, n. 2, p.124-139, mai./ago. 2020
} 
eficiente ele apresenta um modelo de desenvolvimento das atividades em música, que envolve a composição, a apreciação, a performance, a literatura e o desenvolvimento técnico (soma de habilidades). Estas duas últimas sendo atividades periféricas às de envolvimento musical direto, que seria a composição, apreciação e performance, mas estariam integradas a elas. Ele chama o modelo de "Modelo C (L) A (S) P" (BUENO E BUENO, 2009, p. 8431).

Acerca dos princípios de Educação Musical de Swanwick (2003) pensaremos no segundo princípio que pressupõe considerar o discurso musical dos alunos. Como afirma o próprio autor: "Cada aluno traz consigo um domínio de compreensão musical quando chega a nossas instituições educacionais. Não os introduzimos na música; eles são bem familiarizados com ela, embora não a tenham submetido aos vários métodos de análise que pensamos ser importantes para seu desenvolvimento futuro" (SWANWICK, 2003, p. 66-67).

Nesse contexto, conseguimos ampliar as possibilidades dos estudantes através de uma formação que se utiliza de diversas atividades através do (C)L(A)S(P) e considera o discurso musical do aluno.

Outro educador importante para o estudo é Murray Schafer (2001). Esse educador desenvolveu estudos no campo da ecologia acústica e trouxe o conceito denominado soundscape (Paisagem Sonora) que surge pelo seu interesse nas complexidades sonoras ambientais de nossa sociedade contemporânea (FONTERRADA, 2012). Importante ressaltar que Schafer não apresenta um método com práticas e exercícios pré-estabelecidos. Assim, aponta perspectivas e pontos que acredita serem importantes na formação musical.

Para o presente estudo, vale ressaltar dois aspectos que seu trabalho de Educação Musical tem como foco. O primeiro objetiva “apresentar aos alunos, de todas as idades, os sons do ambiente, tratar a paisagem sonora mundial como uma composição musical, da qual o homem é o principal compositor, e fazer julgamentos críticos que levem à melhoria de sua qualidade" (FONTERRADA, 2012, p. 294). Além disso, Schafer (1991) aponta, ainda, a relevância da música oriental para a formação artística e musical no ocidente e assim, ampliação tanto das formas de fazer música como do capital cultural integrado na formação dos estudantes.

Para finalizar essa etapa, recorremos a Dalcroze e sua formação musical direcionada pelo corpo denominada de Rítmica. Para o referido autor, essa proposta

Rev. Caminhos da Educação: diálogos, culturas e diversidades, Teresina, v. 2, n. 2, p.124-139, mai./ago. 2020 
"pretendia desvencilhar o aluno de uma prática mecânica no aprendizado da música, normalmente apoiado na análise, na leitura e na escrita sem a participação do corpo, que ele considera fundamental para a sensibilização da consciência rítmica" (MARIANI, 2012, p. 31). Assim, a música é estudada e vivenciada através do movimento corporal a partir da realidade e especificidade de cada grupo (MARIANI, 2012).

A partir desses autores, podemos ampliar a possibilidade da construção do gosto musical e do habitus propondo atividades musicais direcionadas para a ampliação das perspectivas dos alunos. Assim, esses educadores musicais surgem como embasamento para as possibilidades que serão apresentadas no próximo tópico.

\section{Possibilidades para o trabalho com a diversidade musical}

Durante o texto discutimos acerca do habitus e habitus conservatorial para entendermos acerca da formação, atuação do professor de música e também sobre capital cultural e diversidade musical dialogando com a construção do gosto e da importância de se trabalhar pensando nas especificidades dos estudantes. Além disso, compreendemos também sobre algumas propostas de ensino de música mais progressistas, objetivando ampliar o referencial teórico das possibilidades do trabalho com a diversidade musical.

A partir do exposto, percebemos que esses conceitos nos ajudam a entender mais sobre a diversidade musical dos estudantes e a necessidade de repensar a formação do professor de música. Nesse sentido, torna-se fundamental agora mostrar algumas possibilidades do trabalho com a diversidade musical em sala de aula nos diferentes campos de atuação do professor de música.

Uma das possibilidades de trabalho, nessa perspectiva, pode ter como princípio o diálogo com as experiências musicais prévias dos alunos. Com base nisso, pode-se pensar em uma apreciação musical de maneira crítica através de discussões acerca do repertório de cada estudante, instigando os alunos a interagirem com os colegas a partir dos diversos elementos musicais presentes nas músicas escolhidas. Além disso, pode ser utilizado também o trabalho com improvisação tendo como Rev. Caminhos da Educação: diálogos, culturas e diversidades, Teresina, v. 2, n. 2, p.124-139, mai./ago. 2020 
base os repertórios diversificados que cada estudante apresentou nas discussões e a execução de pequenas composições instigando os alunos ao trabalho criativo musical a partir de suas vivências e de seu capital cultural.

Essa proposta dialoga com Swanwick (2003) tanto na perspectiva do modelo (C)L(A)S(P) como também considerando o discurso do estudante. Assim, a proposta amplia a percepção musical dos alunos de forma mais ampla e crítica. Swanwick (2003, p. 67-68) cita um exemplo em seu livro acerca de estudantes de Papua-Nova Guiné. $\mathrm{O}$ autor afirma que os alunos:

[...] entraram num novo mundo sonoro fazendo e tocando cítaras de sago. Suas respostas às gravações dos músicos de uma tribo distante foram uma mistura de curiosidade e admiração. Essa música estranha começou a "fazer sentido". Fomos capazes de dar um salto imaginativo dentro dessa forma altamente especializada de discurso musical porque estivemos envolvidos, fazendo e tocando cítaras de sago. Ligar a atividade de composição com a performance e a apreciação também permite que diferentes alunos se sobressaiam de formas diferentes (SWANWICK, 2003, p.67-68).

Indo mais além, podemos pensar também no que aponta Schafer (1991) sobre a Paisagem Sonora na contemporaneidade e, a partir de suas ideias, propor uma atividade musical em grupo utilizando a escuta e reconhecimento de sons diversificados do mundo e assim, instigar práticas de composição a partir dessas diferentes sonoridades. Importante ressaltar que:

As propostas de trabalho de Murray Schafer, caracterizadas pela não linearidade, por não se dirigirem a faixas etárias específicas e por não se inserirem, necessariamente, em currículos escolares, são produto de uma postura de vida muito bem-definida pelo autor. Embutidos em sua obra estão muitos dos valores por ele considerados básicos, e que têm como objetivo não apenas o desenvolvimento de posturas criativas e sensíveis para uma ou duas gerações, mas contribuir para a qualidade da vida no planeta. Essa filosofia de vida aponta caminhos presentes em sua obra, explícita ou veladamente, e que devem ser deslindados, para que se compreendam seus princípios e as posições que assume (FONTERRADA, 2012, p. 291).

Outra proposta interessante dialoga com a utilização do corpo como meio de expressão musical. Dessa forma, percebemos a possibilidade do aprendizado e a aplicação de combinações rítmicas utilizando o corpo como instrumento. Trata-se de um espaço, como afirma Simão (2013, p. 41), “de exploração da possibilidade do corpo produzir sons intencionalmente organizados e classificados, que serão posteriormente ordenados em exercícios de coordenação, em ritmos e em jogos

Rev. Caminhos da Educação: diálogos, culturas e diversidades, Teresina, v. 2, n. 2, p.124-139, mai./ago. 2020 
musicais". Tudo isso, aliado com discussões com o grupo acerca do tipo de repertório que pode ser tocado.

Essa proposta pode dialogar também com práticas percussivas africanas, por exemplo, e como elas dialogam com as funções da música e com a formação da música brasileira. Assim, a prática musical pode ser contextualizada e ampliada para além do fazer musical performático. Isso pode acontecer também com músicas de outras culturas que não são tão valorizadas na nossa formação e que muitas vezes perdem seu real sentido diante do tradicionalismo performático da música tradicional européia. Isso é reforçado por Tugny e Queiroz (2006, p. 9 apud DORING, 2017, p. 30) quando apontam que:

Muito se pensou sobre a forma pela qual se confinaram na opacidade as vozes dos xamãs, dos pais de santo, dos capitães do Reinado. Não porque não falem ou não cantem, mas porque suas vozes e suas músicas costumam sofrer um esvaziamento, uma perda de sentido quando chegam aos ouvidos dos brancos: de fato não são escutadas.

\section{Considerações finais}

Este trabalho procurou trazer reflexões acerca da formação do professor de música a partir dos conceitos de habitus e habitus conservatorial. Além disso, ampliou as discussões sobre a influência que o capital cultural exerce na formação do gosto musical das pessoas e objetivou apresentar propostas e possibilidades de como o professor deve lidar com a diversidade musical em sala de aula, uma vez que, em seu processo de formação, a maioria dos professores de música não possui preceitos reflexivos e críticos nesse âmbito.

No que diz respeito às aulas de música, é muito importante que o aluno se sinta valorizado durante a prática docente. Começar sua prática musical estudando um repertório que é familiar a ele, como músicas que fazem parte do meio em que ouve diariamente, torna-se fundamental para o aprendizado musical do estudante. Além disso, o trabalho com a diversidade amplia o fazer musical para além da técnica, podendo ser estendido para a contextualização da peça musical, da apreciação musical e, assim, melhor conscientização do próprio fazer musical.

Para finalizar, é importante ressaltar que se trata de um estudo inicial que objetiva ampliar as possibilidades da atuação do professor de música indo além do

Rev. Caminhos da Educação: diálogos, culturas e diversidades, Teresina, v. 2, n. 2, p.124-139, mai./ago. 2020 
tradicionalismo e da reprodução de práticas excludentes dentro do campo da Educação Musical. Assim, propomos um ensino de música mais multicultural e democrático nos diversos espaços formativos brasileiros.

\section{Referências}

ABREU, Yure Pereira de. Habitus e formação musical de adolescentes: um estudo com estudantes da escola pública. 2018. 124 f. Dissertação (Mestrado) - Curso de Mestrado em Educação, Programa de Pós-graduação em Educação, Universidade Federal do Ceará, Fortaleza, 2018. Disponível em: http://www.repositorio.ufc.br/bitstream/riufc/35877/3/2018_dis_ypabreu.pdf. Acesso em: 10 abr. 2020.

BUENO, Paula Alexandra Reis; COSTA, Rosa Maria Cardoso Dalla; BUENO, Roberto Eduardo. A educomunicação na educação musical e seu impacto na cultura escolar. Educ. Pesqui., São Paulo, v. 39, n. 2, p. 493-507, 2012. Disponível em: https://www.scielo.br/scielo.php?script=sci arttext\&pid=S1517-97022013000200014.

Acesso em: 30 abr. 2020.

BUENO, Paula Alexandra Reis; BUENO, Roberto Eduardo. Uma proposta metodológica para se ensinar música musicalmente. In: CONGRESSO NACIONAL DE EDUCAÇÃO, 9., 2009, Paraná. Anais [...]. Paraná, 2009. p. 8430-8440. Disponível em: https://educere.bruc.com.br/arquivo/pdf2009/3568_2012.pdf. Acesso em: 01 abr. 2020.

BOURDIEU, Pierre. O senso prático. Petrópolis: Editora Vozes, 2009.

BOURDIEU, Pierre. Os três estados do capital cultural. In: NOGUEIRA, Maria Alice; CATANI, Afrânio (Org.). Escritos sobre educação. 13. ed. Petrópolis: Vozes, 2012. Cap. 4.

CAMPOS, V. N. S.; CREPALDE, N. J. B. F. A Musicalização como Forma de Ampliar o Capital Cultural: propostas para uma vivência sem fronteiras: propostas para Uma Vivência Sem Fronteiras. Formação@docente, [s.l.], v. 8, n. 2, p. 20-34, dez. 2016.

DÖRING, Katharina. Ouvindo a diversidade musical do mundo - para uma Educação Musical cognitiva "além das fronteiras". Revista FAEEBA - Ed. e Contemp., Salvador, v.26, n. 48, p. 27- 46, 2017. Disponível em: https://www.researchgate.net/publication/323926617_Ouvindo_a_diversidade_musical_d o_mundo-para_uma_educacao_musical_cognitiva_alem_das_fronteiras. Acesso em: $30 \mathrm{abr}$. 2020 .

FONTERRADA, Marisa Trench de Oliveira. Raymond Murray Schafer: o Educador Musical em um mundo em mudança. In: MATEIRO, Teresa; ILARI Beatriz (Org.). Pedagogias em Educação Musical. Curitiba: Intersaberes, 2012.

FRANÇA, Gustavo Rapozeiro. A Teoria Espiral do Desenvolvimento Musical e a Epistemologia Genética: relações e dissociações entre os pensamentos de keith swanwick e jean piaget. : relações e dissociações entre os pensamentos de Keith Swanwick e Jean Piaget. In: SIMPÓSIO BRASILEIRO DE PÓS-GRADUANDOS EM MÚSICA, 5., 2018, Rio de Janeiro. Anais [...]. Rio de Janeiro, 2018. p. 1-12. Disponível em:

Rev. Caminhos da Educação: diálogos, culturas e diversidades, Teresina, v. 2, n. 2, p.124-139, mai./ago. 2020 
http://www.seer.unirio.br/index.php/simpom/article/view/7715. Acesso em: 02 mar. 2020.

FUCCI AMATO, Rita de Cássia. Breve Retrospectiva Histórica e Desafios do Ensino de Música na Educação Básica Brasileira. Revista Opus, v. 12, p. 144 - 166, 2006. Disponível em: http://www.anppom.com.br/revista/index.php/opus/article/view/319/298. Acesso em: 21 abr. 2020.

LAZZARIN, Luís Fernando. Multiculturalismo e multiculturalidade: recorrências discursivas na educação musical. Revista da ABEM, Porto Alegre, V. 16, n. 19, p. 121-128, mar. 2008. Disponível em: http://www.abemeducacaomusical.com.br/revistas/revistaabem/index.php/revistaabem/ article/view/266/197. Acesso em: 11 abr. 2020.

MAGLIONI, Teisa Bustamante et al. A influência do capital cultural no gosto e no consumo de música, televisão e cinema. Semina: Ciências Sociais e Humanas, [s.l.], Londrina, v. 36, n. 2, p.53-63, 2015.2 Disponível em: http://www.uel.br/seer/index.php/seminasoc/article/view/24362/18878. Acesso em: 30 abr. 2020.

MARIANI, Silvana. Émile Jaques-Dalcroze. A música e o movimento. In: MATEIRO, Teresa; ILARI Beatriz (Org.). Pedagogias em Educação Musical. Curitiba: Intersaberes, 2012.

PENNA, Maura. A dupla dimensão da política educacional na escola: I - analisando a legislação e termos normativos. Revista da ABEM, Porto Alegre, V. 10, p. 19-28, mar. 2004.

PEREIRA, Marcus Vinicius Medeiros. Licenciatura em música e habitus conservatorial: analisando o currículo. Revista da ABEM, Londrina, v. 22, n. 32, p. 90-103, 2014. Disponível em:

http://abemeducacaomusical.com.br/revistas/revistaabem/index.php/revistaabem/article /view/464/388. Acesso em: 12 abr. 2020

RIBEIRO, Robson. Percurso formativo e habitus conservatorial: reflexões a partir da experiência de um professor de música do ensino médio integrado. Anais do SIMPOM, Rio de Janeiro, n. 5, p. 285-295, 2018. Disponível em: https: $/ /$ www.google.com/url?sa $=t \& r c t=j \& q=\& e s r c=s \&$ source $=$ web\&cd $=1 \& v e d=2 a h U K$ Ewi-mrTy-

pXpAhVxGbkGHYsvDJkQFjAAegQIARAB\&url=http $\% 3 \mathrm{~A} \% 2 \mathrm{~F} \% 2 \mathrm{Fwww}$.seer.unirio.br \%2Findex.php $\% 2$ Fsimpom $\% 2$ Farticle $\% 2$ Fdownload $\% 2 F 7729 \% 2 F 6679 \& u s g=A O v V a w 0 a$ MFdEQIwqJXX2EI29pSV. Acesso em: 10 abr. 2020.

SCHAFER, R. Murray. A afinação do mundo. São Paulo: Editora UNESP, 2001.

SCHAFER, R. Murray. O owvido pensante. São Paulo: Fundação Editora da UNESP, 1991.

SIMÃO, João Paulo. Música corporal e o corpo do som: um estudo dos processos de ensino da percussão corporal do barbatuques. 2013. 93 f. Dissertação (Mestrado em Educação) Faculdade de Educação, Universidade Estadual de Campinas, 2013. Disponível em: http://repositorio.unicamp.br/bitstream/REPOSIP/250849/1/Simao_JoaoPaulo_M.pdf. Acesso em: 30 mar. 2020.

Rev. Caminhos da Educação: diálogos, culturas e diversidades, Teresina, v. 2, n. 2, p.124-139, mai./ago. 2020 
SOUSA, Renan Santiago de; IVENICKI, Ana. Sentidos de multiculturalismo: uma análise da produção acadêmica brasileira sobre educação musical. Revista da ABEM, Londrina, v. 24, n. 36, p. 55-70, 2016. Disponível em: http://abemeducacaomusical.com.br/revistas/revistaabem/index.php/revistaabem/article Lview/599/464. Acesso em: 09 abr. 2020.

SWANWICK, Keith. A Basis for Music Education. London: Routledge, 1979.

SWANWICK, Keith. Music, Mind and Education. London: Routledge, 1988.

SWANWICK, Keith. Ensinando Música Musicalmente. Trad. Alda Oliveira e Cristina Tourinho. São Paulo. Moderna, 2003. 